\title{
Palyatif bakım servisinde yatan akciğer kanserli hastaların narkotik analjezik kullanımı
}

\author{
Narcotic analgesic use of hospitalized patients with lung cancer in palliative care service
}

\author{
Hüseyin Can ${ }^{1}$, Gülseren Pamukl, Hilal İkbal Bilyay, ${ }^{1}$ Esra Meltem Koç , Yusuf Cem Kaplan², Yüksel \\ Küçükzeybek ${ }^{3}$, Ahmet Alacacıoğlu
}

${ }^{1}$ Aile Hekimliği Anabilim Dalı, Tıp Fakültesi, İzmir Kâtip Çelebi Üniversitesi, İzmir, Türkiye

${ }^{2}$ Tıbbi Farmakoloji Anabilim Dalı, Tıp Fakültesi, İzmir Kâtip Çelebi Üniversitesi, İzmir, Türkiye

${ }^{3}$ Tıbbi Onkoloji Bilim Dalı, Tıp Fakültesi, İzmir Kâtip Çelebi Üniversitesi, İzmir, Türkiye

\section{ÖZET}

Giriş: Kanser hastalarının yarıdan fazlası hastalığın herhangi bir döneminde yaşam kalitelerini bozan en önemli sorunlardan birisi olan ağrıya maruz kalmaktadır. Bu hastalarda ağrı en kısa sürede azaltılmalı ve idame tedavisi planlanmalıdır. Dünya Sağlık Örgütü kanser hastalarında ağrının şiddetine göre non-opioid, zayıf opioid ve güçlü opioidlerin kullanıldığı 3 basamaklı analjezik merdiven tedavisini önermektedir. Fakat ağrının palyasyonu sağlık çalışanları, hasta ve hasta yakınlarının narkotik analjezikler hakkındaki yanlış düşünceleri nedeniyle \%80'den fazla oranda yapılamamaktadır

Yöntem: Bu çalışmada İzmir Katip Çelebi Üniversitesi Atatürk Eğitim Araştırma Hastanesi Palyatif Bakım ve Destek servisinde 29.07.2013 ile 31.12.2015 tarihler arasında yatan akciğer kanseri tanılı 72 hasta retrospektif olarak ağrı palyasyonu açısından değerlendirildi.

Bulgular: Yaş ortalaması 61,2 = 8,2 yıl olan hastaların \%77,8 (56)'i erkek, \%22,2 (16)'si kadındı. Beslenememe, ağrı, genel durum bozukluğu, nefes darlığı ve bulantı gibi farklı şikayetler ile başvuran hastaların \%27,8(20)'i yalnızca ağrı şikayeti ile başvurmuştu. Yatış süresi ortanca değeri 7 (2-45) gün olan hastaların \%18,1'ine ise herhangi bir analjezik verilmemişti. \%49,2 (29)'si 2. basamak tedavi, \%50,8 (30)'i ise 3. basamak tedavi almıştı. Hastaların yatış endikasyonları ve taburcu olma durumları ile analjezik kullanımı arasında istatistiksel olarak anlamlı ilişki bulunmuştur (

Sonuç: Kanserde yaşam kalitesini olumsuz yönde etkileyen en sık semptom ağrıdır. Ağrı tedavisinin klinisyenler tarafından iyi bilinmesi gerekmektedir. Ağrı tedavisinde başarı, hastayı psikolojik ve sosyal çevresi ile bir bütün olarak ele alan multidisipliner bir yaklaşım ile uygulanan basamak tedavisi ile mümkün olabilecektir.

Anahtar kelimeler: Kanser, palyatif bakım, analjezi

\begin{abstract}
Introduction: Greater than half of cancer patients suffer from the pain, which is the one of the major problems that disrupt the quality of life at, any time during the disease. Pain should be decreased as soon as possible and the maintenance treatment should be planned in these groups of patients. The World Health Organization (WHO) suggests the use of a three-step analgesic ladder approach including non-opioid, weak opioid and strong opioids according to the severity of the pain. However, the pain palliation can't be accomplished in more than $80 \%$ of patients because of the wrong thoughts of health professionals, patients and patients' relatives about narcotic analgesics.

Methods: In this study 72 lung cancer patients, hospitalized between 29 July 2013 to 31 December 2015 at Izmir Katip Çelebi University Atatürk Education and Research Hospital Palliative Care and Support Service were assessed retrospectively about pain palliation.

Results: Patients mean ages $61.2 \pm 8.2$ and $77.8 \%$ (56) were male, and $22.2 \%$ (16) were female. Patients applied with different complaints such as Inability to feed, pain, general condition disorders, shortness of breath and nausea and 27.8\% (20) of patients had only admitted with pain. The median duration of hospital stay was 7 (2-45) days, which is the $18.1 \%$ of patients were not given any analgesics. 49.2\% (29) of patients have second line treatment, 50.8\% (30) had received third line treatment. Hospitalization indication and discharge status of the patients was statistically significant association between analgesic use $(\mathrm{p}=0.002 ; \mathrm{p}=0.03)$.

Conclusion: Cancer pain is the most common symptom affecting the quality of life negatively. Pain management should be well known by clinicians. Success in the treatment of pain patients linked to multidisciplinary approach include the whole psychological and social environment will be possible with the treatment applied by step approach.

Keywords: Cancer, palliative care, analgesia
\end{abstract}

Başvuru / Submission: Temmuz / July 14, 2016

Kabul / Acceptance: Eylül / Sept 12, 2016

Yazışma / Correspondence: Yrd. Doç. Dr. Gülseren Pamuk, İzmir Katip Çelebi Üniversitesi Tıp Fakültesi Aile Hekimliği Anabilim Dalı, İzmir, Türkiye

E-mail:

Atıf / Cite: Can H, Pamuk G, Bilyay Hİ, Koç EM, Kaplan YC, Küçükzeybek Y, Alacacıŏlu A. Palyatif bakım servisinde yatan akciğer kanserli hastaların narkotik analjezik kullanımı. Fam Pract Palliat Care. 2016;1(3):61-64 


\section{GíRiș}

Akciğer kanseri, 20. yüzyılın ortalarından itibaren, özellikle sigara kullanımının artmasıyla beraber önemli sakatlık ve ölüm nedeni olan bir hastalık haline gelmiştir (1). Dünya Sağlık Örgütü (DSÖ) 2014 verilerine göre 2012 yılında dünyada 1,8 milyon yeni akciğer kanseri vakası gelişmiş ve aynı yıl 1,6 milyon kişi kansere bağlı ölmüştür (2). Ülkemiz Sağlık Bakanlığı 2012 verilerine göre 175 bin yeni kanser tanısı konulmuştur. Bu verilere göre akciğer kanseri erkeklerde en sık görülen kanser olmasına rağmen kadınlarda görülen kanserler arasinda 5. sirada yer almaktadır (3).

Hemen her kanser tipinde olduğu gibi akciğer kanseri hastaları da tanı ve tedavi süreci boyunca fiziksel, psikolojik, sosyal pek çok sorun yaşamaktadır. En sık semptom olarak karşımıza çıkan ağrı hastanın günlük aktivitelerini, sosyal ilişkilerini emosyonel durumunu ve yaşam kalitesini olumsuz etkilemektedir. Gün geçtikçe ağrı sıklığının ve şiddetinin artması ile hasta ve hasta yakınları için önemli bir korku kaynağı haline gelmektedir. $\mathrm{Bu}$ açıdan palyatif bakım servislerinin önemi dikkat çekicidir. Dünya Sağlık Örgütü’ne göre tanımı "ağrı ve diğer fiziksel ve psikolojik problemleri erken tanıyıp, değerlendirip, tedavi ederek, yaşamı tehdit eden hastalıklarla ilişkili problemleri önlemek ve rahatlatmak yoluyla, hastaların ve ailelerinin yaşam kalitesini düzeltme yaklaşımı" olan palyatif bakım servisleri sadece yaşamın son döneminde değil, hastalığın her evresinde tıbbi bakım sağlamaktadır $(4,5)$. Nitekim kanser tanısı konulan hastaların \%20-30'u, ileri dönemdeki hastaların ise \%60-100‘ü orta ve şiddetli derecede ağrı çekerler $(6,7)$. Kanser ağrısı tedavisinde genel olarak DSÖ Kanser Ağrısı Tedavisi Programının önerdiği basamak tedavisi kabul edilmektedir (7). Bu yaklaşım ile \%8085 oranında ağrı tedavisi yapılabilmektedir. Geri kalan \%515 'lik kısmın ağrı palyasyonu da uygun invaziv prosedürler ile sağlanabilmektedir (8). Ancak DSÖ, orta-ağır şiddetteki kanser ağrısının, dünya genelinde $\% 80$ oranında yetersiz tedavi edildiğini ve bunun global bir sağlık sorunu olduğunu ilan etmiştir (9). Bunun önemli nedenlerinden biri sağlık personelinin opioidlerin yan etkilerinden özellikle de bağımlılık ve solunum depresyonu yapacağına dair korkusudur. Diğer bir neden de hasta ve hasta yakınlarının ilaçlar ile ilgili yanlış inanışları ve bilgi yetersizliğidir. Bunlar arasında en çok bağımlılık yapacağı düşüncesi ve hastalığının ileri dönemlerinde ilaca karşı tolerans gelişmiş olacağı için ağrısının kontrol altına alınamayacağına dair korkulardır $(10,11)$.

Ağrı tedavisinde esas amaç ağrının hızlı bir şekilde ve kalıcı olarak geçirilmesidir. Hasta ile iyi bir iletişim kurmak, empati yapabilmek ve ağrının geçeceğine dair güven vermek önemlidir. Ağrının şiddetinin belirlenmesinde 0-10 arası ölçüm dereceleri olan sayısal skalalar $(0=$ ağr1 yok, $10=$ ağrı en çok $)$ ve vizüel analog skalalar kullanılarak ağrı objektif olarak değerlendirilmeye çalışılır. Skalada beş ve üzeri ağrı tanımlamaları, hastanın ağrısının önemli olduğunu ve hayat kalitesinin ciddi ölçüde bozulduğunun bir göstergesidir. Buna göre ağrı skala ölçümü 1-4 arası ise hafif ağrı, 5-6 ise orta dereceli ağrı, 7-10 arası ise ciddi ağrı olarak sınıflandırılır (12).

Tedavide analjezik ilaçlar 3 kategoride ele alınır. Bunlar; opioidler, non-opioid analjezikler (parasetamol, asetisalisilik asit, non-steroidal anti-inflamatuvar ilaçlar) ve adjuvan analjeziklerdir. Adjuvan analjezikler normalde ağrı dışında endikasyonu olan fakat özel bazı durumlarda ağrı tedavisinde kullanılan ilaçlardır $(2,13)$. Buna göre hafif düzeyde ağrılar için birinci basamak tedavi olan non-steroidal anti-inflamatuvar (NSAI) ilaçlar gerektiğinde maksimum doza çıkılarak verilir. $\mathrm{Bu}$ analjeziklerin yetersiz kaldığı durumda tedaviye opioid eklemek gerekir. Böylece öncelikle ikinci basamak tedavide yer alan zayıf opioidlerden kodein ya da tramadol verilir. Bu tedaviye rağmen ağrısı devam eden hastaya opioid dozu maksimum düzeye çıkılabilir ya da güçlü opioidlerden morfin, fentanil gibi ajanlar tercih edilebilir. Bunların yanında her basamakta tedaviye adjuvan analjezikler eklenebilir. Basamak tedavisinin başarıya ulaşması için analjezik seçiminin önemi kadar ilacın verildiği uygun yol, uygun doz ve uygun zaman aralığı da önemlidir (14). Hastanın ilk değerlendirilmesi yapıldığında, ağrının şiddeti ve tipine göre gerekirse direk ikinci ya da üçüncü basamak tedaviden başlamak gerekebilir (15). Ayrica son yıllarda zayıf opioidlerin etkinliğinin yüksek doz NSAİ ilaçlardan daha fazla olmadığına dair görüşler ortaya atılmıştır (16). Bu nedenle şiddetli ağrısı olan kişilere 2. basamak tedavi uygulamanın ağrı kontrolünde zaman kaybına yol açtığı düşüncesi oluşmuş, akut ağrı ya da kontrolsüz ağrısı olan hastalarda üst basamak tedavi ile başlayıp kontrol sağlandıktan sonra gerekirse basamak azaltmanın daha uygun olduğu, bunun yanında basamak tedavisinin kronik ağrılarda kullanılabileceği bildirilmiştir (17).

Opioidler uygulama yolu çeşitliliği, güvenilirliği, doz titrasyonunun kolay olması, tüm ağrı tiplerinde etkili olması dolayısıyla kanser ağrısında temel analjezik ilaçlardır (20). Dünyada DSÖ’nün basamak tedavisi kabul görmesine rağmen opioid kullanımına dair bilgi yetersizliği nedeniyle kanser hastalarında ağrı tedavisi etkili bir şekilde yapılamamaktadır $(18,19)$. Çalışmamızda kronik progresif bir hastalık olan akciğer kanserinin seyrinde ölmeden önce ortaya çıkan ve hasta ile yakınları açısından sıkıntı verici bir semptom olan ağrının palyasyonunun değerlendirilmesi amaçlanmıştır.

\section{YÖNTEM}

Retrospektif yapılan bu çalışmada İzmir Kâtip Çelebi Üniversitesi Atatürk Eğitim Araştırma Hastanesi Kanser Hastalarında Palyatif Bakım ve Destek Servisinde 29.07.2013 ile 31.12.2015 tarihler arasında yatan 72 akciğer kanseri tanılı hasta geriye dönük olarak ağrı palyasyonu açısından değerlendirildi. Tüm hastalar yaş, cinsiyet, palyatif bakım servisine yatış nedeni, yatış süresi, taburculuk durumu ile uygulanan narkotik analjezik tedavi açısından değerlendirildi.

\section{Istatistiksel Analiz}

Veriler SPSS 20,0 demo paket programı kullanılarak analiz edildi. Tanımlayıcı analizler normal dağılıyorsa ortalama \pm standart sapma, normal dağllmiyorsa ortanca ve minimummaksimum değerler; sayı (yüzde) şeklinde belirtildi. Gruplar arası karşılaştırmada kategorik değişkenler için Ki-Kare Testi, normal dağılmayan sayısal değişkenler için Mann-Whitney U testi kullanıldı. $\mathrm{p}<0,05$ anlamlı kabul edildi. 


\section{BULGULAR}

Yaş ortalaması 61,2 $\pm 8,2$ yıl olan 72 akciğer kanseri tanılı hastanın verisi tarandı. Hastaların $56(\% 77,8)$ 's1 erkek olup; 24 $(\% 33,3)$ 'ü beslenme yetersizliği, 20 (\%27,8)'si ağrı, 19 $(\% 26,4)$ 'u hem beslenme yetersizliği hem ağrı, $5(\% \quad 6,9)$ 'i nefes darlığ $1,2(\% 2,8)$ 'si genel durum bozukluğu ve $2(\% 2,8)$ 'si bulantı şikâyeti ile yatırılmıştı (Tablo 1).

\section{Tablo 1.Hastaların başvuru şikâyetlerinin dağılımı}

\begin{tabular}{ll}
\hline Başvuru nedeni & $\mathbf{n , ( \% )}$ \\
\hline Beslenme yetersizliği & $24(33,3)$ \\
Ağrı & $20(27,8)$ \\
Beslenme yetersizliği ve ağrı & $19(26,4)$ \\
Nefes darlığı & $5(6,9)$ \\
Genel durum bozukluğu & $2(2,8)$ \\
Bulantı & $2(2,8)$ \\
\hline
\end{tabular}

Yatış süresi 7 (2-45) gün olarak bulundu. Hastaların 44 $(\% 61,1)$ 'ü taburcu, $4(\% 5,6)$ 'ü ise başka bir kliniğe nakil olmuştu. Olguların \%33,3 (24)'ü yatışı sırasında vefat etmişti. Yatış anında ve takiplerinde değerlendirilen hastaların \%40,3'ü sadece tramadol, \%2,8'i sadece fentanil, \%1,4'ü sadece morfin kullanırken; \%23,6's1 hem tramadol hem fentanil, \%13,9'u ise tramadol+fentanil+morfinden oluşan üçlü kombinasyonu kullanmıştı (Tablo 2).

\section{Tablo 2. Hastaların analjezik kullanımına göre dağılımı}

\begin{tabular}{ll}
\hline Analjezik & $\mathbf{n , ( \% )}$ \\
\hline Sadece tramadol kullanan & $29(40,3)$ \\
Sadece fentanil hcl kullanan & $2(2,8)$ \\
Sadece morfin hcl kullanan & $1(1,4)$ \\
Tramadol ve fentanil kullanan & $17(23,6)$ \\
Tramadol ve morfin kullanan & 0 \\
Tramadol, fentanil, morfin kullanan & $10(13,9)$ \\
Hiçbir analjezik kullanmayan & $13(18,1)$ \\
\hline Toplam & $\mathbf{7 2 ( 1 0 0 )}$ \\
\hline
\end{tabular}

Olguların \%18,1'ine ise herhangi bir analjezik verilmemişti. \%49,2 (29)'si 2. basamak tedavi, \%50,8 (30)'i ise 3. basamak tedavi almıştı.

Hastaların yaşı ile yatış endikasyonu, taburculuk durumu ve analjezik kullanımı arasında; cinsiyetleri ile yatış süreleri ve analjezik kullanımları arasında; yatış endikasyonu ile yatış süreleri arasında anlamlı fark bulunmadı (sırasıyla $\mathrm{p}=0,920$; $\mathrm{p}=0,404 ; \mathrm{p}=0,682 ; \mathrm{p}=0,704 ; \mathrm{p}=0,512 ; \mathrm{p}=0,953)$. Hastaların yatış endikasyonları ile analjezik kullanımı değerlendirildiğinde istatistiksel olarak anlamlı bir ilişki bulundu $(\mathrm{p}=0,002)$.

Hastaların hastaneden taburcu olma durumları, analjezik kullanımları ile karşılaştırıldığında istatistiksel olarak anlamlı ilişki bulunmasına $(\mathrm{p}=0,03)$ rağmen yatış süreleri açısından ilişki görülmedi $(p=0,316)$. Benzer şekilde yatış süreleri ile analjezik kullanım durumları arasında da istatistiksel anlamlı ilişki bulunmadı $(\mathrm{p}=0,556)$

\section{TARTIŞMA}

Toraks derneği çalışma grubunun 11849 akciğer kanserli hasta üzerinde yaptığı çalışmada olguların \%56,7'sinin 46-65 yaş arasında yer aldığı1, \%90,4'ünün erkek cinsiyet olduğu bildirilmiştir (21). Çalışmamızda olguların yaş ortalaması 61,2 y1l olup, \%77,8'i erkek cinsiyet olarak tespit edilmiştir.

Kayhan ve arkadaşlarının yaptığı bir çalışmada ağrı tedavisi için \%61 zayıf opioid (\%27,8 tramadol, \%14,9 kaşe, \%18,3 kaşe+tramadol kombinasyonu), \%9,1 güçlü opioid $(\% 6,2$ transdermal fentanil, \%2,9 hidromorfon) ve \%29,9 zayıf + güçlü opioid kombinasyonu (\%18,3 tramadol+transdermal fentanil kombinasyonu, \%6,2 kaşe+tramadol+transdermal fentanil kombinasyonu, \%5,4 kaşe+transdermal fentanil kombinasyonu) tercih edilmiştir (22).

Çalışmamızda hemen hemen benzer oranlarda analjezik kullanımı saptanmasına rağmen, tek başına güçlü opioid kullanımının daha az olduğu ve hidromorfon tedavisinin servisimizde kullanılmadığı tespit edilmiştir.

Çalışmamızda hastaların \%49,2'si ikinci basamak, \%50,8'i üçüncü basamak tedavi almıştı. Zech ve arkadaşları 2117 kanserli hasta üzerinde geriye dönük olarak yaptıkları çalışmada, hastaların \%11,1'inin birinci, \%31,1'inin ikinci, \%49'unun da üçüncü basamak tedavi aldıkları bildirilmiştir (23). Orhan ve arkadaşları ise yaptıkları bir çalışmada birinci basamak tedavi alanları \%11,7, ikinci basamak tedavi alanları $\% 73.79$ ve üçüncü basamak tedavi alanları ise \%14.42 olarak bulmuşlardır (24). Kurşun ve arkadaşları 1736 hastada geriye dönük yaptıkları çalışmada da hastaların $\% 5,2$ 'sinin birinci basamak, \%57,6'sının ikinci basamak, \%22,8'inin de üçüncü basamak tedavi aldıklarını göstermişlerdir (25). Diğer çalışmalardan farklı olarak bizim çalışmamızda birinci basamak tedavi yer almamıştır. Bunun nedeninin hasta grubumuzun palyatif bakım ve destek servisinde yatan ileri dönem akciğer kanseri tanılı hastalar olmasından kaynaklandığını düşünmekteyiz. Çünkü bu hastalar genellikle birinci basamak ağrı tedavisine yeterli yanıt alamadıkları için servisimize yönlendirilmektedirler.

Sonuç olarak, kanserde yaşam kalitesini olumsuz yönde etkileyen en sık semptom ağrıdır. Öncelikle ağrı tedavisinin klinisyenler tarafindan iyi bilinmesi gerekmektedir. Klinisyenler ve hastalar çoğu zaman bağımlılık yapacağı korkusu ile opioid tedavisinden uzak durmaktadır. Aslında kronik ağrı hastalarında opioid bağımlılığı sanılandan çok daha nadirdir (26-28). Bununla beraber yaşlı ve düşkün hastalarda opioidlere bağlı solunum depresyonu olabileceği endişesi, gerçekte olduğundan çok daha fazladır ve bu durum opioidlere başlama ve doz artımında çekingenliklere neden olmaktadır (29). Hasta ve yakınlarına palyatif bakım merkezlerinde opioidlerin maksimum dozu olmadığı, yan etkilerin önlenebilir ve geçici olduğu, bağımlılığın sanılandan çok daha az olduğu gibi bilgiler ayrıntılı olarak anlatılmalıdır. Ağrı tedavisinde başarı, hastayı psikolojik ve sosyal çevresi ile bir bütün olarak ele alan multidisipliner bir yaklaşım ile uygulanan basamak tedavisi ile mümkün olabilecektir. 
Çıkar çatış̧ması: Bildirilmedi.

Finansal destek: Bildirilmedi.

\section{KAYNAKLAR}

1. Jemal A, Bray F, Center MM, Ferlay J, Ward E, Forman D. Global cancer statistics. CA Cancer J Clin 2011;61:6990 .

2. Brambilla E, Travis WD. Lung cancer. In: World Cancer Report, Stewart BW, Wild CP (Eds), World Health Organization, Lyon 2014.

3. Türkiye Kanser İstatistikleri, Ankara, 2015. Erişim yeri: http://kanser.gov.tr/Dosya/kayitcilik/ANA_rapor_2012so oonn.pdf Erişim tarihi: 06.05.2016

4. Meier DE, Bishop TF. Palliative care; benefits, services, and models of care. www.uptodate.com, version19.2, last updated: May 13, 2011.

5. World Health Organization definition of palliative care, avaliable online

at

http:/www.who.int/cancer/palliative/definition/en (Accessed on October 20, 2011).

6. M Costantini M, Ripamonti C, Beccaro M, et al. Prevalence, distress, management, and relief of pain during the last 3 months of cancer patients' life. Results of an Italian mortality follow-back survey. Ann Oncol 2009;20:729-35.

7. Sarihan E, Kadioglu E, Igde FA. Kanser agrisi, tedavi prensipleri ve Dünya Saglik Orgutu agri basamak tedavisi. Nobel Med 2012;8:5-15.

8. Breivik H, Cherny N, Collet $\mathrm{F}$ et al. Cancer related pain: A pan European survey of prevelance, treatment andpatient attitudes. Ann Oncol 2009;20:1420-33.

9. World Health Organization. Access to controlled medications programme: Framework. Geneva, Switzerland: WHO Document Production Services; 2007. Available

at: http://www.who.int/medicines/areas/quality_safety/Frame work_ACMP_withcover.pdf Accessed May,6,2016.

10. Von Roen JH, Cleeland CS, Gonin R, et al. Physician attitudes and practice in cancer pain management. A survey from the Eastern Cooperative Oncology Group. AnnIntern Med 1993;119:121-6.

11. Ward SE, Goldberg N, Miller- McCaulay V, et al. Patient related barriers to management of cancer pain. Pain 1993;52:319-24.

12. Caraceni A, Cherny N, Fainsinger R, et al. The Steering Committee of the EAPC Research. Pain measurement tools and methods in clinical research in palliative care: recommendations of an expert working group of the European Network. Association of Palliative Care. J PainSymptom Manage 2002;23:239-55.

13. Siegel RL, Miller KD, Jemal A. Cancer statistics, 2016. CA Cancer J Clin 2016;66:7.

14. Scottish Inter collegiate Guidelines Network. Control of Pain in adults with cancer: A National Clinical Guideline. SIGN-Scottish Intercollegiate Guidelines Network. Edinburgh, November 2008. ISBN 9781905813384

15. Michael H, Levy MD. Pharmacologic treatment of cancer pain. N Engl J Med 1996; 335(15):1124-31.
16. Francis OJ, Minerva PC. Opioid use in the Philippines-20 years after the introduction of WHO Analgesic Ladder. Eur J Pain 2007;1:19-22.

17. Vargas-Schaffer G. Is the WHO analgesic ladder still valid? Twenty-four years of experience. Can Fam Physician 2010;56:514-7.

18. Mcquay HJ, Moore RA. Opioid problems and morphine metabolism and excretion. In: Dickenson AH, Besson JM(eds) The Pharmacology of Pain, Berlin Heidelberg:Springer-Verlag;1997:335-360.

19. Deandrea S, Montanari M, Moja L, et al. Prevalence of undertreatment in cancer pain. A review of published literature. Ann Oncol 2008;19:1985-91.

20. Cherny NI, Baselga J, De Conno F, et al. Formulary availability and regulatory barriers to accessibility of opioids for cancer pain in Europe: a report from the ESMO/EAPC Opioid Policy Initiative. Ann Oncol 2010;21:615-26.

21. Turkish Thoracic Society, Lung and Pleural Malignancies Study Group. Pattern of lung cancer in Turkey 1994-1998. Respiration2002;69:207-10.

22. Kayhan GE, Gulhas N, Aslan A, et al. Algoloji Poliklinigine Başvuran Onkolojik Hastalarda Tedavi ve Komplikasyon Yonetimi: Retrospektif Degerlendirme. J Turgut Özal MedCent2013:20(1):50-54

23. Zech DF, Grond S, Lynch J, et al. Validation of World Health Organization Guidelines for cancer pain relief: a 10-year prospective study. Pain 1995;63(1):65-76.

24. Orhan ME, Bilgin F, Ergin A, et al. Pain treatment practice according to the WHO analgesic ladder in cancer patients: eight years experience of a single center. Agri 2008;20(4):37-43.

25. Kursun YZ, Yildiz F, Kaymaz O, Onal SA. Agrili Kanser Hastalarinin Tedavisinde Analjezik Basamak Tedavisinin Yeri. Agri 2015;27(1):26-34.

26. Porter J, Jick H. Addictionrare in patients treated with narcotics. N Engl J Med 1980;302:123.

27. Fishbain DA, Rosomoff HL, Rosomoff RS. Drug abuse, dependence, and addiction in chronic pain patients. Clin J Pain1992;8:77-85.

28. McQuay HJ. Opioid use in chronic pain. Acta Anaesthesiol Scand 1997;41:175-83.

29. Kuzeyli Yildirim Y, Uyar M. Etkili Kanser Agri Yonetimindeki Bariyerler. Agri 2006;18:12-9. 